\title{
Management of Maxillary First Molar with Six Canals using Cone Beam Computed Tomography
}

\author{
${ }^{1}$ Nidha Madan, ${ }^{2}$ Harshita Gwalani, ${ }^{3}$ Deepak Raisingani, ${ }^{4}$ Ashwini Prasad, ${ }^{5}$ Harshit Srivastava
}

\begin{abstract}
The probability of morphologic variations in a tooth should never be misconstrued and the cognition of these variations is the cue to successful endodontic treatment. The form, configuration, and number of root canals in maxillary first molar have been studied for more than half a century. An anatomic variation like three canals in the distal root of maxillary first molar is not frequently reported. Apart from a properly designed access cavity, well-angulated radiographs, and routine use of loupes, the practitioner should consider using cone beam computed tomography as an auxiliary method for detecting complex root canal anatomy. This clinical case report presents the successful management of maxillary first molar with six root canals with the use of computed tomography scans as a diagnostic aid.
\end{abstract}

Key Messages: The incidence of second distobuccal canal ranges from 1.64 to $9.5 \%$. However, the incidence of third distal canal (distopalatal) is rare $(<1 \%)$. This report highlights the importance of computed tomography in the successful diagnosis and management of maxillary first molar.

Keywords: Cone beam computed tomography, Maxillary first molar, Six canals.

How to cite this article: Madan $\mathrm{N}$, Gwalani $\mathrm{H}$, Raisingani $\mathrm{D}$, Prasad A, Srivastava H. Management of Maxillary First Molar with Six Canals using Cone Beam Computed Tomography. J Oper Dent Endod 2017;2(1):36-39.

Source of support: Nil

Conflict of interest: None

\section{INTRODUCTION}

A detailed knowledge of both normal and abnormal anatomies of root canal system is an essential prerequisite for successful endodontic therapy. ${ }^{1}$ The maxillary first molar is considered one of the most complex teeth in the dental arch. The first molar typically has three distinct roots and three or four canals. ${ }^{2}$ These teeth are frequently

\footnotetext{
${ }^{1}$ Resident (3rd Year), ${ }^{2}$ Resident (1st Year), ${ }^{3}$ Professor and Head ${ }^{4}$ Reader, ${ }^{5}$ Senior Lecturer

${ }^{1-5}$ Department of Conservative Dentistry and Endodontics Mahatma Gandhi Dental College \& Hospital, Jaipur, Rajasthan India

Corresponding Author: Harshita Gwalani, Resident (1st Year) Department of Conservative Dentistry and Endodontics Mahatma Gandhi Dental College \& Hospital, Jaipur, Rajasthan India, Phone: +911412770300, e-mail: dr.harshitagwalani@ gmail.com
}

observed with the presence of three roots (two buccal and one palatal) along with three or four root canals. ${ }^{3}$ The incidence of second mesiobuccal (18.6-96.1\%), second distobuccal (1.6-9.5\%), mesiopalatal (56.8\%) and prevalence of distopalatal $(1.7 \%)$ canals are reported in various studies. ${ }^{4-8}$ Previous morphologic data indicate that the palatal canals usually have a lower degree of curvature and a larger internal diameter than mesiobuccal and distobuccal canals. Variations in the number, shape, and curvature of palatal canals have been reported, which further indicate the importance of additional investigations with more accurate methods. ${ }^{9}$

This case report describes the intricacy of maxillary first molar with an unusual morphology of three roots and six canals (two mesiobuccal, two distobuccal, distopalatal, and palatal) which has neither been reported in any clinical or laboratory studies nor clinical case reports so far. This unusual morphology was confirmed with the aid of cone-beam computed tomography (CBCT) scanning.

\section{CASE REPORT}

A 23-year-old male patient reported to the Department of Conservative Dentistry and Endodontics with the chief complaint of spontaneous pain and discomfort to thermal stimuli in the maxillary right posterior region for past 2 days. The medical history was noncontributory. On clinical assessment, maxillary right first molar had deep occlusal caries and responded positively to palpation and percussion; tooth mobility was within the physiologic limits and gingival attachment was normal. Vitality testing of the offending tooth with dry ice (R C Ice; Prime Dental Products, India) induced an intense lingering pain, whereas electric pulp testing (Denshine Technology Co., Ltd, Hong Kong) produced a premature response. Intraoral periapical (IOPA) radiograph of the tooth \#16 evinced large occlusal radiolucency involving enamel, dentin, and the pulp chamber along with widening of periodontal ligament space in the distobuccal root (Fig. 1). After meticulous clinical and radiographic assessment, a diagnosis of symptomatic irreversible pulpitis with symptomatic apical periodontitis was established and endodontic therapy was recommended to the patient. Receiving the patient's consent, the treatment was initiated. The offending tooth was anesthetized with $1.8 \mathrm{~mL}$ of $2 \%$ lignocaine containing 1:200,000 epinephrine 


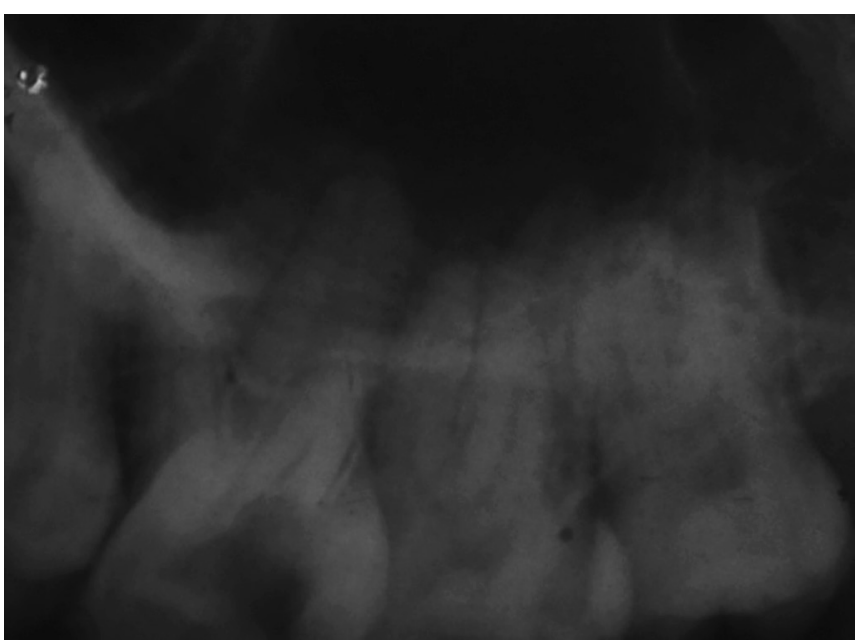

Fig. 1: Preoperative radiograph of tooth \#16

(Xylocaine; AstraZeneca Pharma Ind. Ltd., Bangalore, India). Under absolute rubber dam isolation, access cavity preparation was performed using Endo Access Kit (Dentsply, Pennsylvania) (Fig. 2). The chamber floor inspection using DG 16 endodontic explorer (Hu-Friedy, Chicago, Illinois) under 2.5× magnification (Heine, Germany) revealed presence of three main root canal openings: Mesiobuccal, distobuccal, and palatal. The distal canal orifice appeared to be more constricted than routine anatomy indicating an astute radiographic analysis. The conventional triangular access was modified to a trapezoidal shape to improve access to additional canals. To ascertain the presence of additional canals in the mesiobuccal and distobuccal roots and to determine the aberrant anatomical architecture of the tooth, a CBCT scan was performed. The CBCT slices of tooth \#16 confirmed the presence of six canals: Two mesiobuccal, two distobuccal, one distopalatal, and palatal (Fig. 3). The

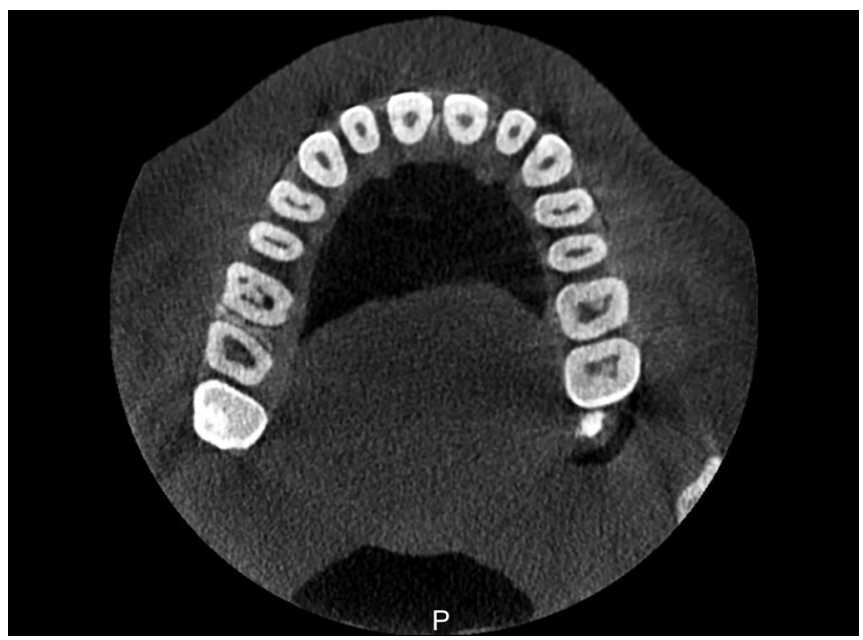

Fig. 3: Cone beam computed tomography axial slice of tooth \#16 at coronal level indicating the presence of third distal (distopalatal) canal

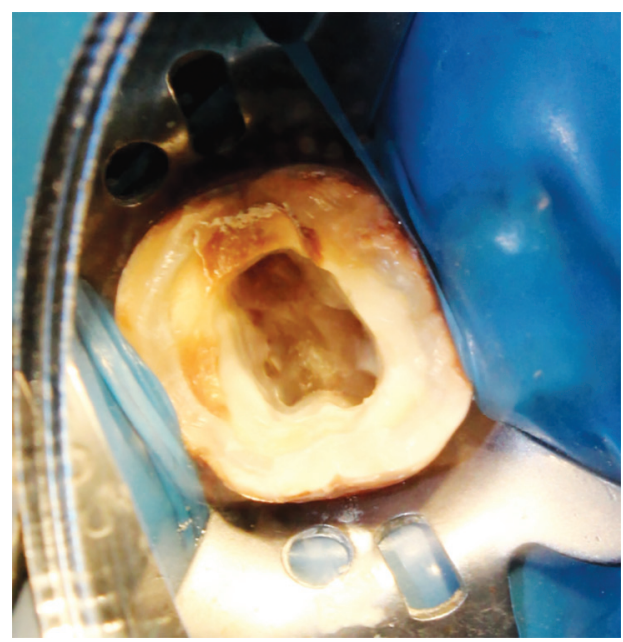

Fig. 2: Endodontic access showing the opening orifices of mesiobuccal (MB1 and MB2), distal (DB1, DB2, and distopalatal), and palatal canals

CBCT scans provided valuable information regarding the canal configuration and confirmed the six canals that were not appreciated in the conventional radiograph. These images are reconstructed using significantly lower radiation doses compared with conventional periapical radiography. In $\mathrm{CBCT}$ scanning, the raw data are acquired during a single sweep of a cone-shaped X-ray source and reciprocal detector around the patient's head. The patient was asymptomatic on the subsequent visit; considering the available information, additional canals were located and instrumented. Working lengths of canals were determined using electronic apex locator (Propex II Dentsply) and confirmed radiographically (Fig. 4). The cleaning and shaping of mesiobuccal, mesiobuccal 1, distobuccal, distobuccal 2, and distopalatal was performed using Hero Shaper File (Micro-Mega) \#20 and \#25 (4 and $6 \%$ ). The palatal canal was cleaned and shaped using Protaper Files (Dentsply) (MAF = F2). Obturation was

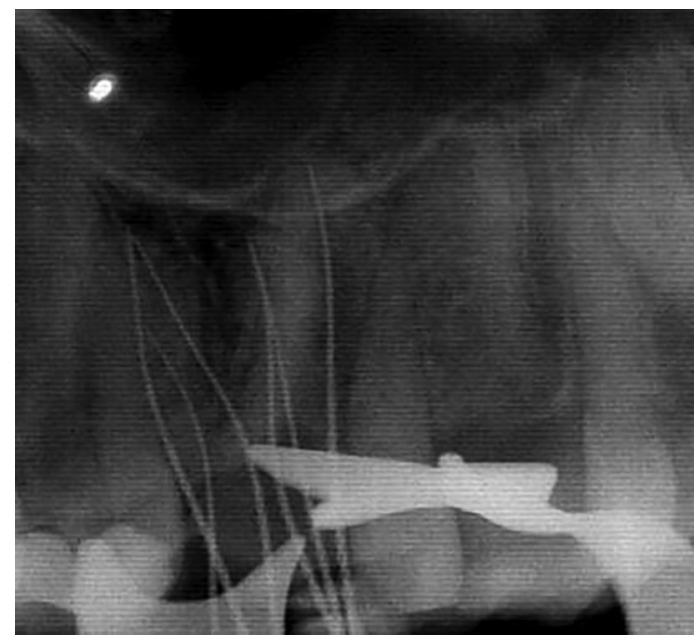

Fig. 4: Working length determination 


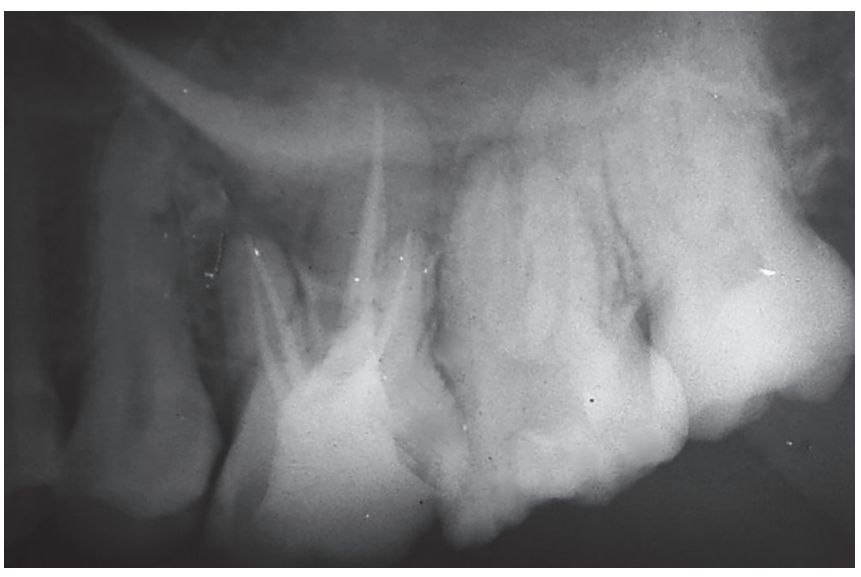

Fig. 5: Postobturation radiograph

accomplished with lateral compaction technique using gutta-percha points (Dentsply Maillefer, Switzerland) and AH plus resin sealer (Dentsply, De Trey, Germany) (Fig. 5). The tooth received a permanent posterior composite resin core (3M Filtek P60) and was advised a fullcoverage porcelain crown (Fig. 6).

\section{DISCUSSION}

Successful endodontic therapy depends on meticulous cleaning and shaping of the entire pulp space along with complete obturation of the root canal system. The prime reason for failure of endodontic therapy is the incompetence to detect extra roots or root canals. ${ }^{10}$ Various methods, such as clinical assessment, dye staining, tooth sectioning, scanning electron microscope, radiographs and magnification, etc., have been used for detecting additional canals for both in vitro as well as in vivo evaluation. ${ }^{11}$ With CBCT scans, it is possible to diagnose unusual root canal anatomy, whereas IOPA radiography is confined to producing two-dimensional image of threedimensional anatomies. The CBCT has expedited access to root canal morphology by allowing the clinician to examine multiple slices of tooth roots and root canals. ${ }^{12,13}$ Maxillary first molars have immense variability with respect to number of roots, canals, and anatomy. Extensive studies have deduced that maxillary first molar with three roots and four canals should be considered as the rule rather than the exception. ${ }^{14}$ Hence, case reports with unusual canal configurations and anomalies of maxillary first molar are of utmost didactic importance. The subsequent elements contribute to the variation found in root canal system of maxillary first molar, namely ethnic background, age, gender of the population studied, design, and methods of the study. ${ }^{15,16}$ Variations in the root canal anatomy concerning distobuccal, distopalatal, and palatal roots are very infrequent $(<1 \%)$; nonetheless, their existence should be thoroughly scrutinized. ${ }^{6}$ Recent advances in diagnostic technology have led to a paradigm

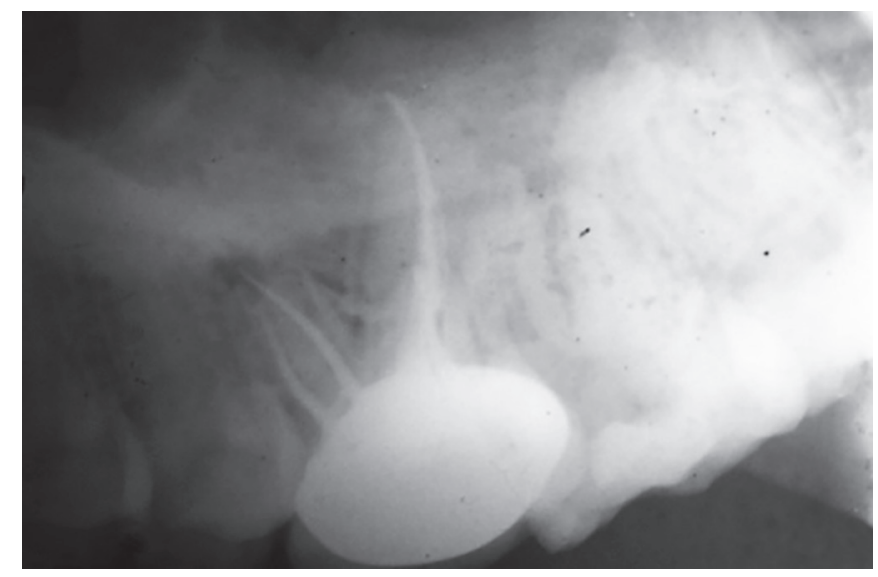

Fig. 6: Crown cementation radiograph

shift, and therefore, CBCT is of paramount importance in dental imaging.

\section{CONCLUSION}

The possibility of missing canal(s) during endodontic therapy is high because of the anatomic variations of the root canal system. The CBCT is a proficient threedimensional view diagnostic tool.

\section{REFERENCES}

1. Vertucci FJ. Root canal anatomy of the human permanent teeth. Oral Surg Oral Med Oral Pathol 1984 Nov;58(5):589-599.

2. Versiani MA, Pécora JD, Sousa-Neto MD. Microcomputed tomography analysis of the root canal morphology of singlerooted mandibular canines. Int Endod J 2013 Sep;46(9): 800-807.

3. Ingle, JI.; Bakland, L., editors. Endodontics. 5th ed. Hamilton (ON): BC Decker; 2002.

4. Hartwell G, Bellizzi R. Clinical investigation of in vivo endodontically treated mandibular and maxillary molars. J Endod 1982 Dec;8(12):555-557.

5. Sert S, Bayirli GS. Evaluation of the root canal configurations of the mandibular and maxillary permanent teeth by gender in the Turkish population. J Endod 2004 Jun;30(6): 391-398.

6. Cleghorn BM, Christie WH, Dong CC. Root and root canal morphology of the human permanent maxillary first molar: a literature review. J Endod 2006 Sep;32(9):813-821.

7. Alaçam T, Tinaz AC, Genç O, Kayaoglu G. Second mesiobuccal canal detection in maxillary first molars using microscopy and ultrasonics. Aust Endod J 2008 Dec;34(3):106-109.

8. Umer F. Maxillary first molar with five canals. BMJ Case Rep 2014 Sep;2014.

9. Versiani MA, Pécora JD, de Sousa-Neto MD. Root and root canal morphology of four-rooted maxillary second molars: a micro-computed tomography study. J Endod 2012 Jul;38(7):977-982.

10. Slowey RR. Radiographic aids in the detection of extra root canals. Oral Surg Oral Med Oral Pathol 1974 May;37(5):762-772.

11. Baratto Filho F, Zaitter S, Haragushiku GA, de Campos EA, Abuabara A, Correr GM. Analysis of the internal anatomy of maxillary first molars by using different methods. J Endod 2009 Mar;35(3):337-342. 
12. Betancourt P, Navarro P, Cantín M, Fuentes R. Cone-beam computed tomography study of prevalence and location of MB2 canal in the mesiobuccal root of the maxillary second molar. Int J Clin Exp Med 2015 Jun;8(6):9128-9134.

13. Di Lorenzo P, Niola M, Buccelli C, Re D, Cortese A, Pantaleo G, Amato M. Professional responsibility in dentistry: analysis of inter-departmental case study. Dent Cadmos 2015;83: 324-340.
14. Pineda F, Kuttler Y. Mesiodistal and buccolingual roentgenographic investigation of 7,275 root canals. Oral Surg Oral Med Oral Pathol 1972 Jan;33(1):101-110.

15. Weine FS, Hayami S, Hata G, Toda T. Canal configuration of the mesiobuccal root of the maxillary first molar of a Japanese sub-population. Int Endod J 1999 Mar;32(2):79-87.

16. Ross IF, Evanchik PA. Root fusion in molars: incidence and sex linkage. J Periodontol 1981 Nov;52(11):663-667. 